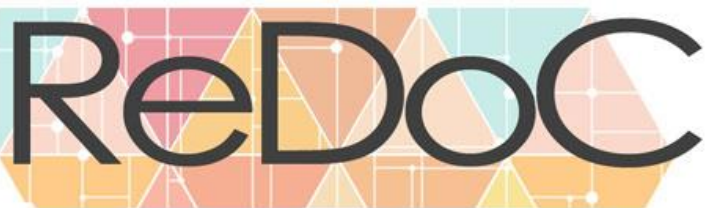

Revista Docência e Cibercultura

\title{
APRENDER NO FACEBOOK: ALGUNS SILÊNCIOS E RUÍDOS PARA INVESTIGAR O ENSINO E A DOCÊNCIA ONLINE
}

\section{LEARN ON FACEBOOK: SOME SILENCES AND NOISES TO INSTIGATE EDUCATION AND TEACHING ONLINE}

\section{APRENDER EN EL FACEBOOK: ALGUNOS SILENCIOS Y RUIDOS PARA INVESTIGAR LA ENSEÑANZA Y LA DOCENCIA EN LINE}

\author{
Bruno Vieira Alves da Silva ${ }^{1}$ \\ Marcelo Almeida Bairral ${ }^{2}$
}

\begin{abstract}
Resumo: Cada vez mais as tecnologias da informação e comunicação (TIC) tornam mais rápida e dinâmica a comunicação, a interação e o compartilhamento de conteúdo entre as pessoas. Essa investigação busca refletir sobre contribuições do Facebook como espaço de aprendizagem em uma disciplina do Mestrado em Educação do PPGEduc/UFRRJ. A disciplina transcorreu em sua maior parte no Facebook e os participantes tiveram oportunidade de explorar as ferramentas disponibilizadas no grupo e de refletir coletivamente a partir de diferentes propostas de discussão. Os dados foram gerados a partir das interações no próprio grupo. O software Nodelx foi utilizado para analisar a não
\end{abstract}

Submetido em: 15/05/2018 - Aceito em: 24/05/2018 - Publicado em: 29/06/2018.

1 Graduado em Pedagogia pela UFRRJ - Instituto Multidisciplinar (2008 - 2012). Pós-graduado em Planejamento, Implementação e Gestão da Educação a Distância - UFF (2013 - 2015) Mestre em Educação do Programa de Pós-Graduação, Contextos Contemporâneos e Demandas Populares - PPGEduc/UFRRJ (2015 - 2017) Bolsista CAPES. Instrutor Voluntário de Teatro na ONG: Escola Livre FAMA desde agosto de 2014 até o presente momento. Professor de Informática Educativa do Colégio Pedro II (2017). Orcid: https://orcid.org/0000-0001-7044-9733 Lattes: http://lattes.cnpq.br/8048592378227746 E-mail: brunovieira009@hotmail.com

${ }^{2}$ Licenciado (1990) e especialista (1992) em Matemática pela Universidade Federal Fluminense, mestre em Educação Matemática pela Universidade Santa Úrsula (1996), doutor em Educação Matemática pela Universidade de Barcelona (2002) e pós-doutor em Educação Matemática pela Universidade do Estado de Nova Jersey (EUA, 2007) e pela Universidade de Turin (Itália, 2012). É professor associado IV do Instituto de Educação da Universidade Federal Rural do Rio de Janeiro. Preside o Gepem desde 2003 e é o editor responsável do Boletim Gepem. Fundador e coordenador do Grupo de Estudos e Pesquisas da TIC em Educação Matemática (www.gepeticem.ufrrj.br). Idealizador e coordenador da Série InovaComTic da Editora da UFRRJ (Edur). Foi coordenador e atua como docente do Programa de Pós-Graduação em Educação, Contextos Contemporâneos e Demandas Populares (PPGEduc/UFRRJ). É também professor do Programa de Pós-Graduação em Educação em Ciências e Matemática (PPGEduCIMAT/UFRRJ). Foi coordenador do GT19 (Educação Matemática) da ANPEd e membro da coordenação do GT6 (Educação Matemática: Novas Tecnologias e EaD) da SBEM. Em julho de 2013 passou a integrar a Comissão internacional para melhoria do ensino e da aprendizagem de matemática (CIEAEM). mbairral@ufrrj.br http://lattes.cnpq.br/0159010164759435

https://orcid.org/0000-0002-5432-9261 


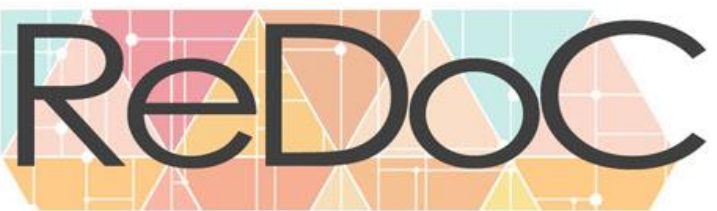

Revista Docência e Cibercultura

linearidade e a hipertextualidade presentes no processo interativo nesta rede. A análise elucida ruídos e silêncios observados na dinâmica interativa neste grupo. Ruídos foram caracterizados a partir das interações relacionadas às discussões que aconteciam no grupo. Como silêncios são denominados os rastros silenciosos dos membros ao utilizar a rede, mesmo sem interagir nela.

Palavras-chave: Facebook; Análise de interações; Grupo fechado no Facebook; Disciplina optativa.

Abstract: Increasingly, information and communication technologies (ICTs) are rapidly making communication, interaction and sharing of content between people a breeze. This research seeks to reflect on the contributions of Facebook as a learning space in an optional course of Postgraduate Education. The group was an elective subject of the MSc Academic in Education of the PPGEduc/UFRRJ. The discipline was mostly spent on Facebook and participants had the opportunity to explore the tools available in the group and to reflect collectively from different emerging discussion proposals. The data were generated from the interactions in the group. Nodelx software was used to analyze the nonlinearity and hypertextuality present in the interactive process in this network. As results, the research elucidates noises and silences observed in the interactive dynamics in this group. Noises were characterized from the interactions related to the discussions that took place in the group. And as silences are characterized the silent trails of the members when using the network, that is, the long period of time without interacting in the network.

Keywords: Facebook; interactions analysis; closed group on Facebook; optional course

Resumen: Cada vez más las tecnologías de la información y la comunicación (TIC) hacen más rápida y dinámica la comunicación, la interacción y el intercambio de contenido entre las personas. Esta investigación busca reflejar sobre las contribuciones de Facebook como espacio de aprendizaje en una disciplina de la Maestría en Educación del PPGEduc / UFRRJ. La disciplina transcurrió en su mayor parte en Facebook y los participantes tuvieron la oportunidad de explorar las herramientas disponibles en el grupo y de reflexionar colectivamente a partir de diferentes propuestas de discusión. Los datos se generaron a partir de las interacciones en el propio grupo. El software Nodelx fue utilizado para analizar la no linealidad y la hipertextualidad presentes en el proceso interactivo en esta red. El análisis eluciona ruidos y silencios observados en la dinámica interactiva en este grupo. Los ruidos se caracterizaron a partir de las interacciones relacionadas con las discusiones que ocurrían en el grupo. Como silencios se denominan los rastros silenciosos de los miembros al utilizar la red, incluso sin interactuar en ella.

Palabras claves: Facebook; Análisis de interacciones; Grupo cerrado en Facebook; Disciplina optativa.

\section{INTRODUÇÃO}

\begin{tabular}{l|l|l|l|l|l|l|} 
CC Redoc & Rio de Janeiro & v.2 & n.2 & p.69 & Maio/Agosto. 2018 & ISSN 2594-9004
\end{tabular}




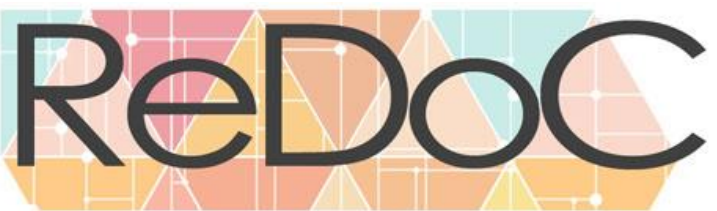

Revista Docência e Cibercultura

Este artigo é recorte de uma dissertação que analisa a experiência de uma disciplina optativa de mestrado conduzida em um grupo fechado no Facebook (da SILVA, 2017). O propósito principal foi refletir sobre contribuições da rede social Facebook como espaço de aprendizagem em uma disciplina optativa de Pós-Graduação em Educação. Concretamente, encontramos na rede social dados os quais nomeamos de silêncios e ruídos. Que ruídos e silêncios a pesquisa em educação nesta rede social podem ser capturados na produção do conhecimento neste campo? Que ruídos e silêncios podemos indicar ou querer assumir nesse modo de fazer pesquisa?

Com esse intuito, buscamos suscitar reflexões sobre o uso da rede social Facebook como mais um espaço possível de aprendizagem e, portanto, essa utilização demanda práticas de ensino e de pesquisa inovadoras e construtivas de outras formas de aprendizado e de descoberta conjunta para professores e alunos. Também, demanda novos modos de fazer pesquisa e de produzir conhecimento.

\section{FACEBOOK: UM GRUPO A PARTE}

O Facebook foi criado por um jovem de 19 anos (Mark Zuckerberg), em um alojamento de estudantes em Harvard, que em pouco tempo conseguiu alterar a forma de comunicação entre as pessoas, ou seja, encurtou a distância de um modo síncrono e assíncrono com forma estética simples, que acabou agradando seus usuários. A rede social criada por Zuckerberg tem sido ferramenta capaz de provocar revoluções e rebeliões entre o povo e seus governantes. Houve um crescimento e expansão considerável desta rede social. A simplicidade visual e estética do Facebook, tem agregado usuários com interesses variados que ficam horas logados na rede.

A rede social Facebook foi a que mais cresceu na última década e durante este crescimento acabou sendo responsável por diversos movimentos que começam na rede, vão para as ruas e continuam nas mãos dos sujeitos com os seus dispositivos móveis. Será que outra mídia social teria uma reação nesta proporção? A internet de um modo geral, acabou quebrando a hegemonia existente em relação a criação de conteúdos e notícias. 


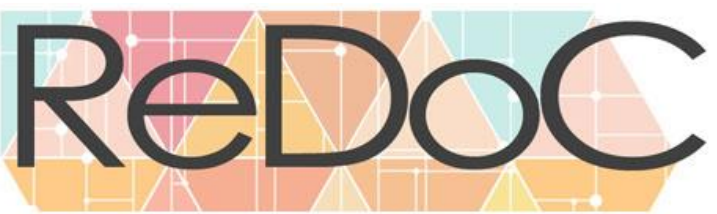

Revista Docência e Cibercultura

Onde poucos produziam para muitos, sendo estes conteúdos e notícias por muito tempo aceitos como únicos e verdadeiros.

De acordo com o levantamento das mídias sociais mais acessadas no Brasil, como Facebook, Instagram, Twitter e YouTube foi possível chegar ao seguinte resultado, baseado no site de ranqueamento de acessos alexa $(2015)^{3}$. O Facebook é o segundo site mais acessado no mundo, perdendo somente para o Google, o YouTube é o terceiro, o Twitter o décimo e o Instagram vigésimo oitavo. O Brasil é o segundo país do mundo onde mais se acessa Facebook, responsável por 4,0\% dos acessos mundiais. O YouTube fica em quarto mais acessado no Brasil, responsável por 3,7\% dos acessos mundiais. O Twitter em décimo primeiro, já o Instagram fica em décimo sétimo.

Por ser o segundo site mais usado no mundo e ter ferramentas que podem ser exploradas para o viés educacional, mesmo que não tenham sido criadas com este intuito, é possível observar que há pessoas que exploram as suas ferramentas para o uso educacional. Inclusive na própria pós-graduação da UFRRJ o uso dos grupos fechados nas disciplinas obrigatórias e em outras disciplinas optativas também era recorrente. No entanto, o uso era desdobrado em troca de mensagens e local de compartilhar os arquivos que seriam discutidos nas aulas presenciais, ou seja, a rede era apenas um meio que dava continuidade ao que acontecia nos encontros presenciais e não o espaço de interação das aulas.

Dessa forma, resolvemos explorá-la na pós-graduação, dessa vez com o oferecimento de uma a disciplina optativa, onde nossas discussões aconteceriam naquele espaço e exploraríamos os recursos disponíveis no grupo. Sendo assim, foi criado um grupo fechado na rede social Facebook, que foi utilizado como espaço primordial para nossas discussões e interações.

Figura 1 - Página inicial do grupo ${ }^{4}$

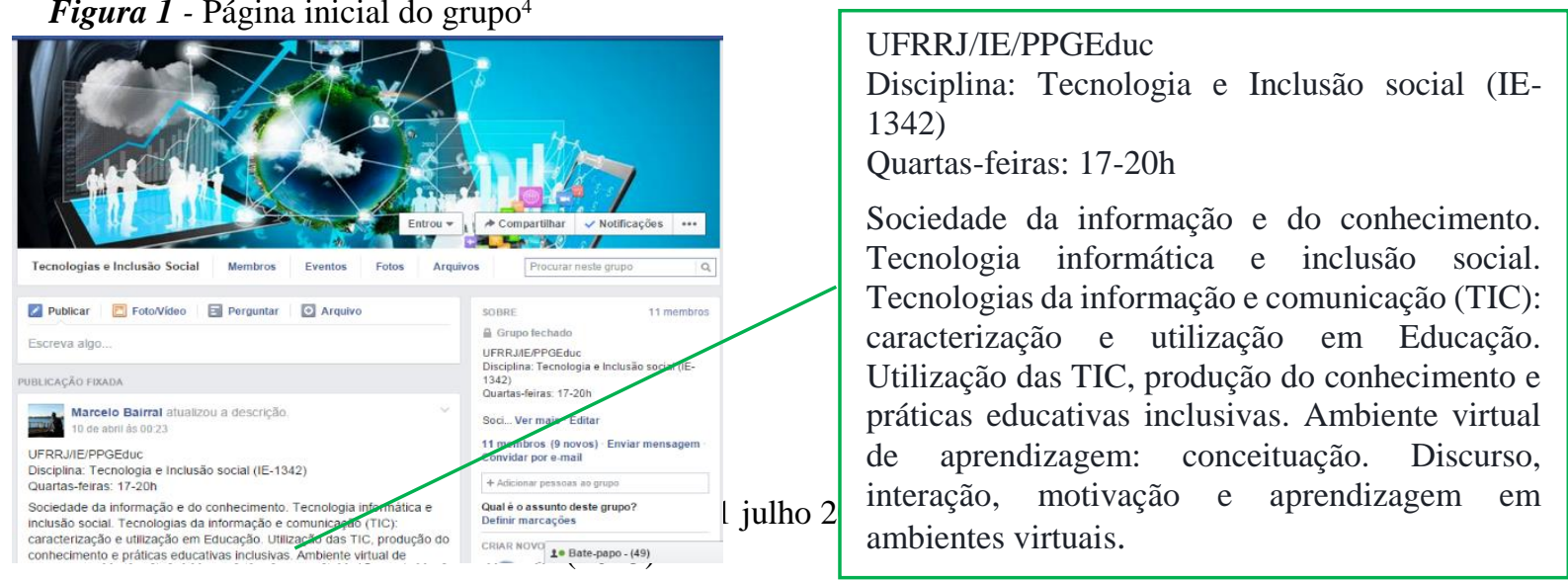


A imagem acima representa o nosso espaço de aprendizagem no Facebook. Onde nos encontrávamos para debater assuntos voltados para os textos propostos. Embora o horário e o dia da aula ocorressem as quartas-feiras das 17:00 às 20:00 horas, nossas interações sempre perpassavam dias da semana e fins de semanas mantendo a dinâmica hipertextual. (LÉVY, 1993).

\section{NO QUE VOCÊ ESTÁ PENSANDO? AMBIENTE VIRTUAL DE APRENDIZAGEM OU FACE?}

Nosso primeiro problema, preocupação ou ruído aconteceu antes de decidirmos sobre o uso do Facebook como plataforma para a realização da disciplina. Será que vai dar certo, esta dinâmica na rede social? A decisão de escolher uma rede social como espaço de interação de uma disciplina de mestrado, foi uma questão política de trabalhar de certa forma a contemporaneidade. Para realização da disciplina, o grupo que contou com gestão e planejamento semanal, que nos orientou durante o período de aulas. Nossas escolhas, nossas interações, foram vivenciadas na rede, apesar da volatilidade e plasticidade do Facebook, ela também trouxe possibilidades de registros.

Bairral (2010) ao conceituar o AVA, descreve alguns componentes que acha necessário e fundamental para a constituição do mesmo. Apesar da disciplina acontecer no grupo do Facebook, as formas de interação (síncrona e assíncrona) são bem parecidas entre a rede social e o AVA. Entretanto, as formas de comunicação no Facebook são bem mais instantâneas do que no AVA. No caso do AVA o que talvez tenhamos mais delimitados são os espaços comunicativos (chat, e-mail, fórum, mensagens etc.). Para 


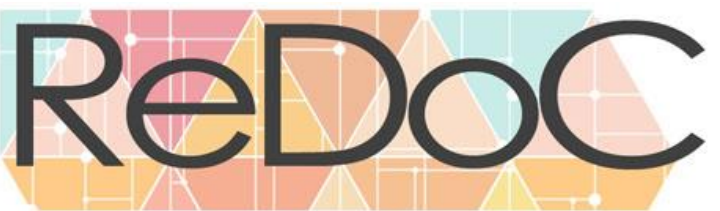

Revista Docência e Cibercultura

saber o que acontece em um chat ou fórum precisamos logar, entrar no AVA e acessar cada um desses espaços.

Diferente do que acontece no Facebook, que acaba sendo a extensão da vida dos usuários. Por exemplo, ao acordar a pessoa pega o celular e confere as notificações que receberam durante o período que estiveram dormindo e podem publicar coisas de seu cotidiano. O AVA não tem a mesma característica de ser a extensão da vida dos alunos e sim um espaço onde as pessoas acessam para "estudar", se especializar etc. A dinâmica do Facebook é bem diferente do AVA, pois o Facebook está a todo momento avisando a seus usuários sobre a atualização na rede. No AVA para saber sobre qualquer coisa que acontece no fórum o participante ou recebe um e-mail ou tem que acessar o fórum, algo que não acontece no Facebook.

Saímos então dos nossos prédios (que seriam os AVAs), onde nem todos sabem que podem ter acesso, e fomos à periferia da cidade (rede social Facebook) ver como acontece, como é feita a pesquisa em um ambiente onde todos se "sentem em casa" e que se pode ter acesso com mais facilidade. O acesso pelo Facebook nos facilitou bastante, possibilitando a mobilidade de estar logado, em nossas contas pelo celular e verificar as notificações avisando quem publicou e quando publicou. Diferente do que acontece no AVA onde os alunos têm que estar sempre logando para ver se há novas publicações e as entregas de tarefas no AVA, na maioria dos casos, são enviadas em documentos no Word, PDF, Power point, que sempre exigem maior ligação do usuário ao desktop.

A disciplina ocorreu no primeiro semestre de 2015 e, por acontecer em uma rede social, todos estavam presentes por seus avatares na rede e a relação social acontecia através das interações das postagens dos membros sobre as opiniões que eram demandadas no decorrer da disciplina. Desse modo, os membros tinham acesso às novas publicações, ou seja, eles eram avisados através de uma notificação no globo do Facebook onde poderiam curtir, comentar, concordar, discordar, aumentando desta forma as interações e os hipertextos que apareceram durante a disciplina. Ao contrário, em um AVA, é comum encontrarmos participantes esquecendo senhas, tendo que atualizar seus 


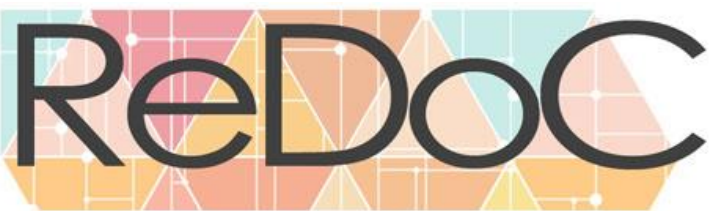

\title{
Revista Docência e Cibercultura
}

dados cadastrais de acesso e ficando muitas vezes dependentes do seu e-mail, ferramentas não muito usuais entre jovens e adolescentes.

Outro ponto que foi pensado e repensado seria não trazer a dinâmica da sala de aula presencial, para a rede social. Já que a disciplina estava acontecendo em um ambiente diferente do tradicional, teríamos que usar as ferramentas e a linguagem daquele espaço que seria usado como disciplina. Sem quadro, sem giz, sem cadeiras enfileiradas. O curso foi planejado, com ementa, com atividades e datas de entregas, supervisionado e direcionado pelo professor responsável da disciplina. Para Bairral (2007, p. 33)

\begin{abstract}
Quando pensamos em implementar um curso ou qualquer atividade formadora, devemos ter consciência das especificidades do ambiente de aprendizagem a ser implementado. (...) No caso da dinâmica a distância, por envolver espaços físicos e tempos diferentes, o planejamento e a estruturação do cenário são imprescindíveis e exigem um trabalho organizacional prévio significativo. A elaboração e proposição de tarefas constituem um grande desafio.
\end{abstract}

A programação do curso foi baseada em trabalhar a relação da tecnologia com a inclusão social durante as quinze semanas, explorando as ferramentas e funcionalidades no grupo do Facebook como as que existem no AVA. Como por exemplo, a comunicação assíncrona, ou seja, em tempos diferentes. As pessoas postam seus comentários no fórum de discussão do AVA, em determinado horário e os outros participantes interagiam em outros horários. Igual aconteceu no Facebook onde os membros publicavam em seus murais e a partir daí os outros alunos respondiam em horários distintos.

Na comunicação síncrona, ou seja, ao mesmo tempo, de acordo com o cronograma da disciplina teríamos dois chats obrigatórios e aconteceu outro chat opcional, onde todos deveriam estar logados ao mesmo tempo para discutir os conceitos e dúvidas existentes durante as aulas no Facebook. Embora a disciplina tenha acontecido em um espaço online onde estamos acostumados a usar (Facebook), não foi preciso a ambientação como acontece no AVA, que geralmente é de uma semana. O fato de todos os participantes já terem sua conta no Facebook e saber usá-las ajudou bastante nesse processo. No nosso caso, assim que foi solicitada a primeira atividade, a mesma já foi publicada no grupo que gerou e desdobrou em comentários, curtidas e levantamentos de questionamentos. 


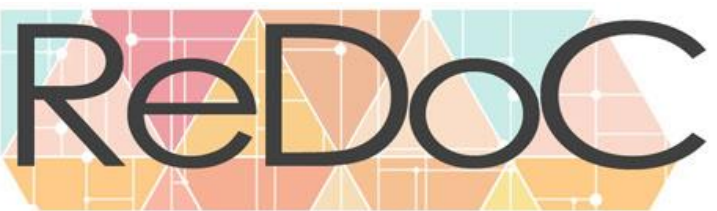

Revista Docência e Cibercultura

A relação espaço e tempo tendo como aliada a mobilidade ubíqua, onde não precisávamos estar em um mesmo lugar físico em determinado horário, foi bem explorada pelos membros e possibilitou que os mestrandos e mestrandas participassem de suas casas, trabalhos, da rua, de qualquer lugar que houvesse conexão com a internet. Houve um caso, onde uma aluna precisou se mudar para outro estado, no decorrer do semestre, por questões pessoais, e aproveitando o fato da disciplina optativa ser on-line ela conseguiu concluí-la. Caso a disciplina optativa fosse presencial se tornaria um pouco mais trabalhoso para aluna. Como afirmou Bairral (2007, p. 35)

A formação a distância possibilita uma flexibilidade diferente de um projeto presencial. Cada conjunto de tarefas é realizado segundo um cronograma pré-estabelecido e divulgado no início de cada curso. Alguns cursos são organizados por unidades temáticas, outros por semanas. São propostas atividades para serem realizadas coletivamente.

Estar on-line na rede e presente nas discussões, mesmo que em outro espaço físico, nos ajudou bastante, pelo fato de cada um ter a flexibilidade de criar seu horário de estudo, de comentar e realizar as atividades no Facebook, usando, inclusive, seu celular.

Após o término da aula no Facebook foi feita a análise do grupo onde garimpamos por dados e encontramos nos rastros da rede social dados que chamamos de ruídos e silêncios.

\section{ALGUNS SILÊNCIOS NO GRUPO}

As informações que o Facebook deixa registrado, são os dias e horários que os membros publicam, comentam, inserem alguma imagem etc. Por outro lado, não registra o horário da curtida nem o (s) dia (s) que os membros visualizam os comentários da publicação ou curtem outros comentários que acontecem no decorrer das interações. Tendo como base, os dados que o Facebook fornece nos rastros deixados na rede, as análises partem destes rastros que foram encontrados durante a pesquisa. 


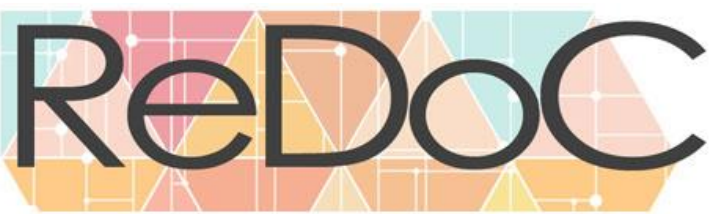

Revista Docência e Cibercultura

Portanto, considero como silêncio na rede, a ausência de comunicação que houve em alguns momentos, de troca de hipertextos, de informações, de novas postagens, novas interações. Considero também o silêncio presente nas postagens que não se desdobram em nada, ou seja, alguém publica, todos visualizam e não acontece nada. Abaixo segue os exemplos onde esse processo de silêncio acontece.

Figura 2 - Exemplo (1) de "silêncio" na rede

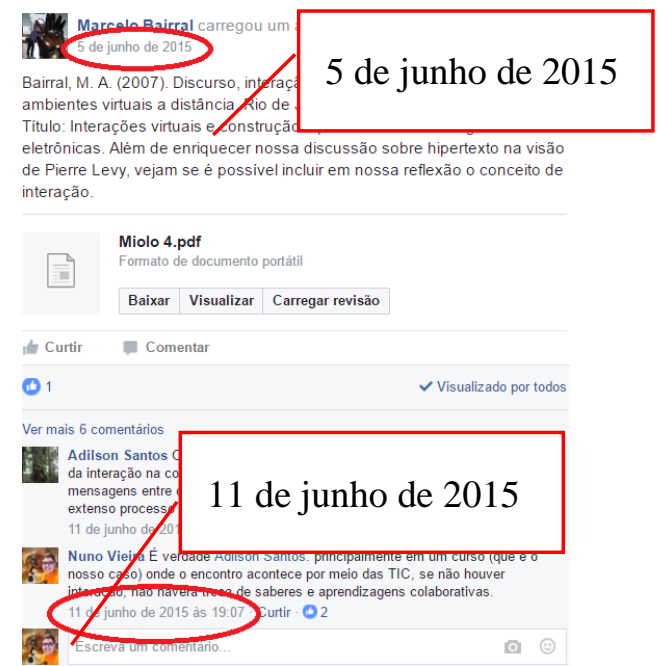

Figura 3 - Exemplo (2) de "silêncio" na rede

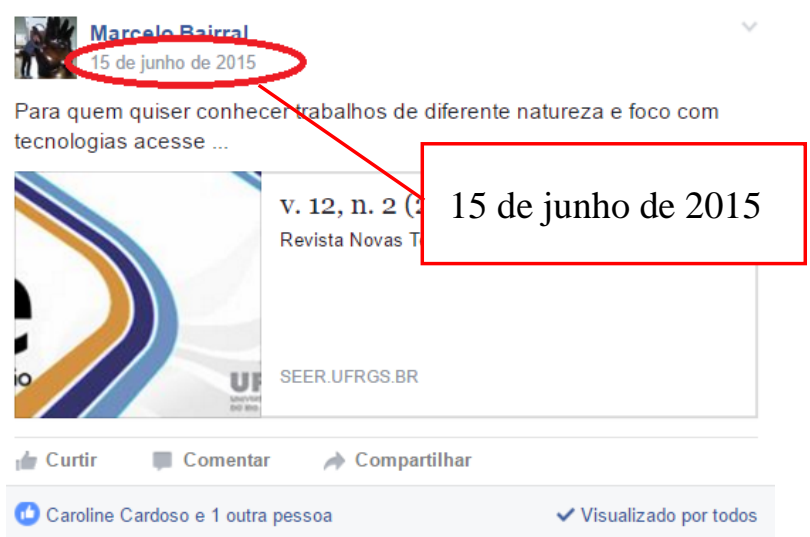

Fonte: Elaboração própria a partir de print de telas.

Fonte: Elaboração própria a partir de print de telas.

Na figura 2, buscamos mostrar quando aconteceu a publicação e quando foi o último comentário. A publicação foi feita no dia 05/06 e teve seu término, ou melhor, o último comentário no dia 11/06, ou seja, durante seis dias ficamos interagindo a partir desta publicação. Comparando com a figura 3, é possível verificar que só ocorreu outra publicação no dia 15/06. Durante este interstício podemos notar que não houve nenhum tipo de comunicação, é este ocorrido que chamo de silêncio. 


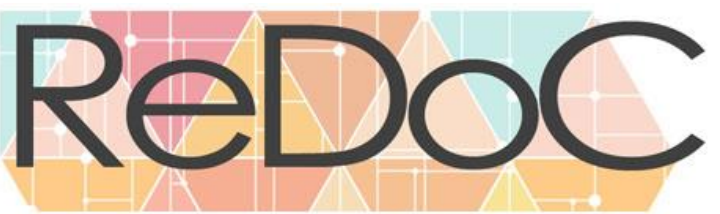

Revista Docência e Cibercultura

Este intervalo de tempo, sem nenhum contato dos membros do grupo entre si, na rede, foi um dos exemplos encontrado para tentar mostra o que chamamos de silêncio em um grupo na rede social. Entretanto, se pegarmos outro (s) momento (s) de análise encontraremos casos parecidos. Da mesma forma como aconteceu com os ruídos, o que será explicado posteriormente. O tema sobre silêncio e ruído será aprofundado com mais detalhes na metodologia.

\section{ALGUNS RUÍDOS NO GRUPO}

Trouxemos, então, para o nosso contexto de grupo na rede social, considerando como ruído qualquer publicação que se desdobre em outros comentários, outros hiperlinks e hipertextos, que não houvesse um intervalo grande entre uma postagem e outra. Além disso, consideramos também, como ruído qualquer ação que provocada pelos membros gerassem notificações e as visualizações que geram comentários. Retratarei abaixo o que considerei como os ruídos que encontrei na rede.

Figura 4 - Exemplo (1) "ruídos" no grupo do Facebook

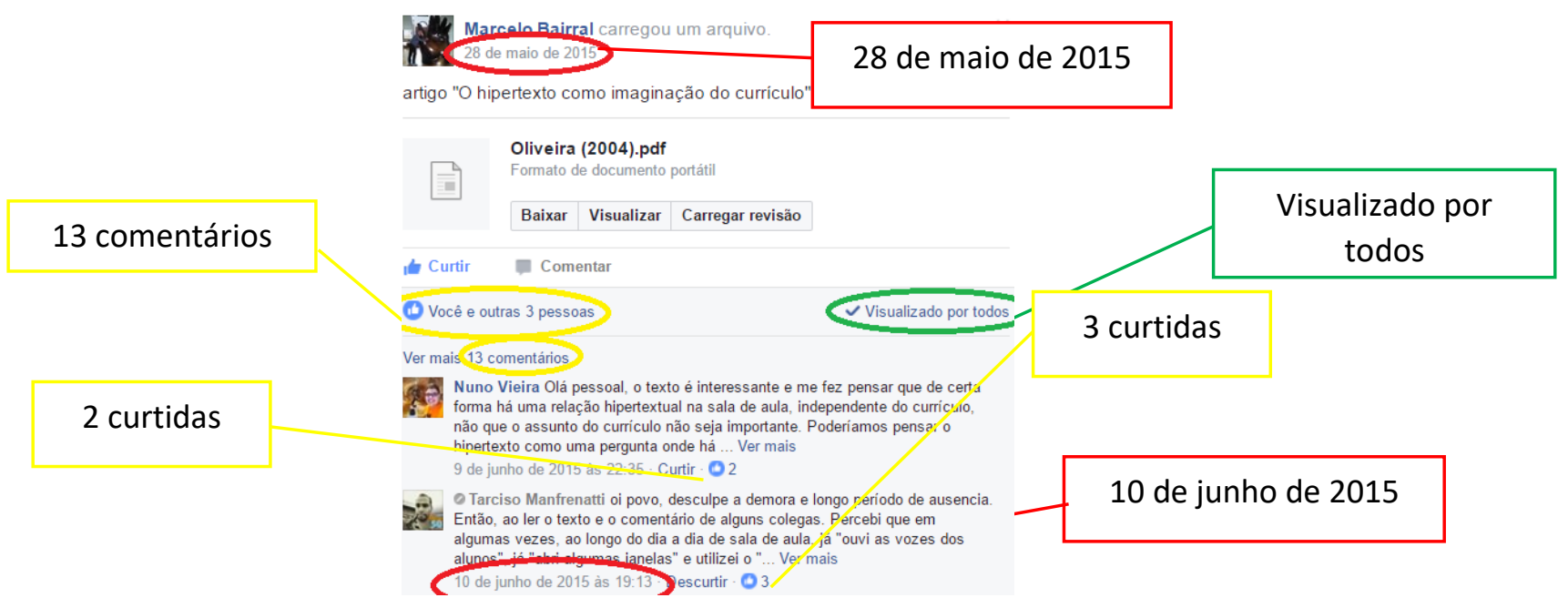

Fonte: Elaboração própria a partir de print de telas. 


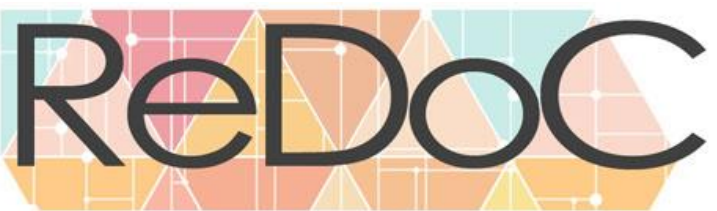

Revista Docência e Cibercultura

Figura 5 - Exemplo (2) "ruídos" no grupo do Facebook

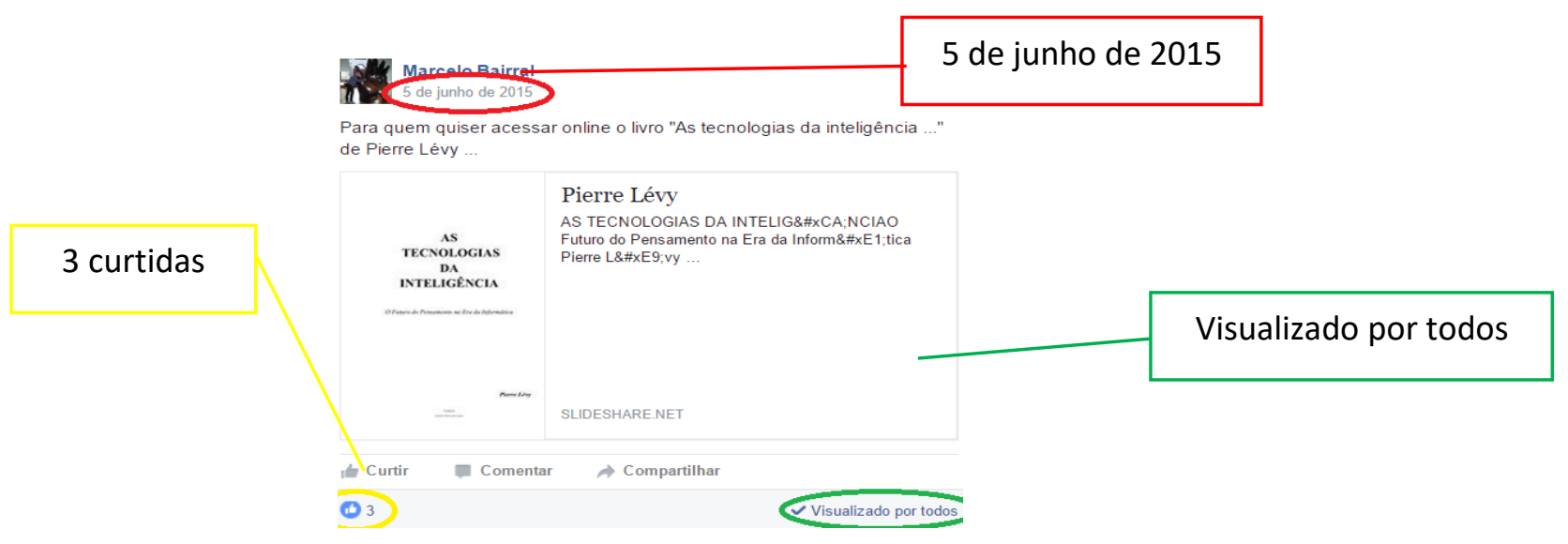

Fonte: Elaboração própria a partir de print de telas.

Analisando as imagens anteriores, temos os elementos que foram considerados como ruídos. Em vermelho, na primeira imagem destacada a data da publicação que foi no dia 28/05/15 e teve o término da interação no dia 10/06/15. Comparando com a segunda imagem, podemos verificar que Bairral publicou um livro online no dia 05/06/15, sendo assim, mesmo que estive ocorrendo interação na rede entre os dias 28/05 e 10/06 na mesma publicação, a rede ainda estava em movimento, através de outras postagens.

Continuando a análise, em verde, podemos ver nas duas imagens que todos os membros do grupo visualizaram as postagens. Essas visualizações que aconteceram em outras publicações e não se desdobraram em nada, como já foi dito anteriormente. Em amarelo, sinalizo as curtidas que as publicações e os comentários que se desdobraram a partir das publicações receberam durante as interações no grupo. O tema sobre silêncio e ruído será aprofundado com mais detalhes na metodologia.

\section{ASPECTOS METODOLÓGICOS}

Por estarmos pesquisando em uma rede social, optamos por utilizar a observação on-line, participante, pois os autores estavam implicados. Macedo (2015, p. 370) nos lembra que nas pesquisas on-line o campo de observação é o ciberespaço", um cenário 


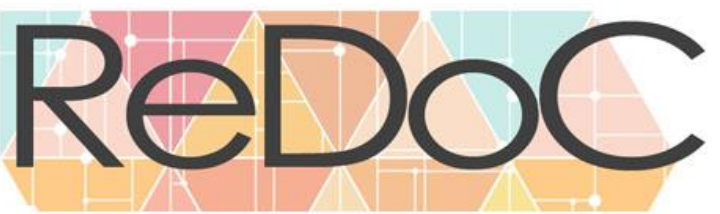

Revista Docência e Cibercultura

no qual o discurso se manifesta de diferentes formas. Concordando com Mendes (2009, p. 6).

Como o pesquisador qualitativo se interessa em analisar seus objetos em contextos naturais, a preferência deve ser por ambientes experimentais.(...). A observação e o ato de tomar notas ao mesmo tempo não são um problema em pesquisas online. Além disso, no espaço virtual, a presença física tanto do pesquisador quanto dos entrevistados é simulada.

Portanto, a pesquisa on-line aconteceu em um espaço experimental, que seria o grupo do Facebook utilizado como um espaço virtual para realização da disciplina. Nele foi possível trabalhar com diversos hipertextos, além de explorar a linguagem por meio da escrita, do uso e compartilhamento de imagens, vídeos etc.

A disciplina ocorreu em quinze semanas e as interações aconteciam por meio de postagens referentes aos textos disponibilizados, comentários, curtidas, além de integrações de outros conteúdos, sendo por fotos, imagens ou vídeos.

A produção e análise dos dados ocorreu após o término da disciplina. A partir das análises de nossas postagens e nossas interações no curso, trabalhamos quatro conceitos: tecnologia; inclusão social; interação e hipertexto. Segue abaixo a tabela com a linha do tempo das nossas discussões sobre esses conceitos:

\begin{tabular}{|l|l|l|l|l|}
\hline Tecnologia & Inclusão Social & Hipertexto & Interação & Hipertexto \\
\hline 09/04/15 a 30/04/15 & $02 / 05$ a $10 / 05$ & $\mathbf{2 9 / 0 4}$ a 13/06 & $05 / 06$ a 02/07 & 02/07 a 20/07 \\
\hline
\end{tabular}

Tabela 1 - Linha do Tempo - Elaboração própria.

O hipertexto, por ter sido um tema recorrente e nossas discussões acontecerem a partir deste conceito, as observações das interações aconteceram entre os dias 29/04 a 13/06 e 02/07 a 20/07. Nelas foram observadas as formas de comunicação que o Facebook permite ao usuário e desdobramentos do que foi construído durante este período.

\section{ANALISANDO SILÊNCIOS E RUÍDOS NO GRUPO}




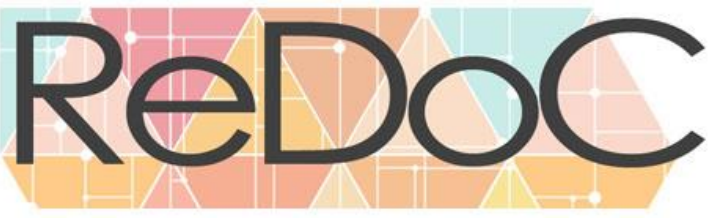

Revista Docência e Cibercultura

Para analisar o silêncio e ruído na rede, buscamos fazer o mapeamento do grupo todo desde a primeira até a última interação na rede, dessa vez o foco desta análise não foi o conceito trabalhado e sim o comportamento dos membros no grupo. O intuito foi verificar se realmente houve momentos em que a rede ficou "silenciosa"/"ruidosa" independentemente do conceito trabalhado. Foi feito o levantamento das datas que houve silêncio e ruídos. No esquema abaixo, será retratado as datas em que a rede ficou "silenciosa". Para organizar os dados produzidos, utilizamos como recurso o software Nodel $x^{5}$, onde inserimos os dados no que gerou os seguintes resultados dos dias em que o grupo ficou silencioso.

Esquema 1 - Os silêncios na rede

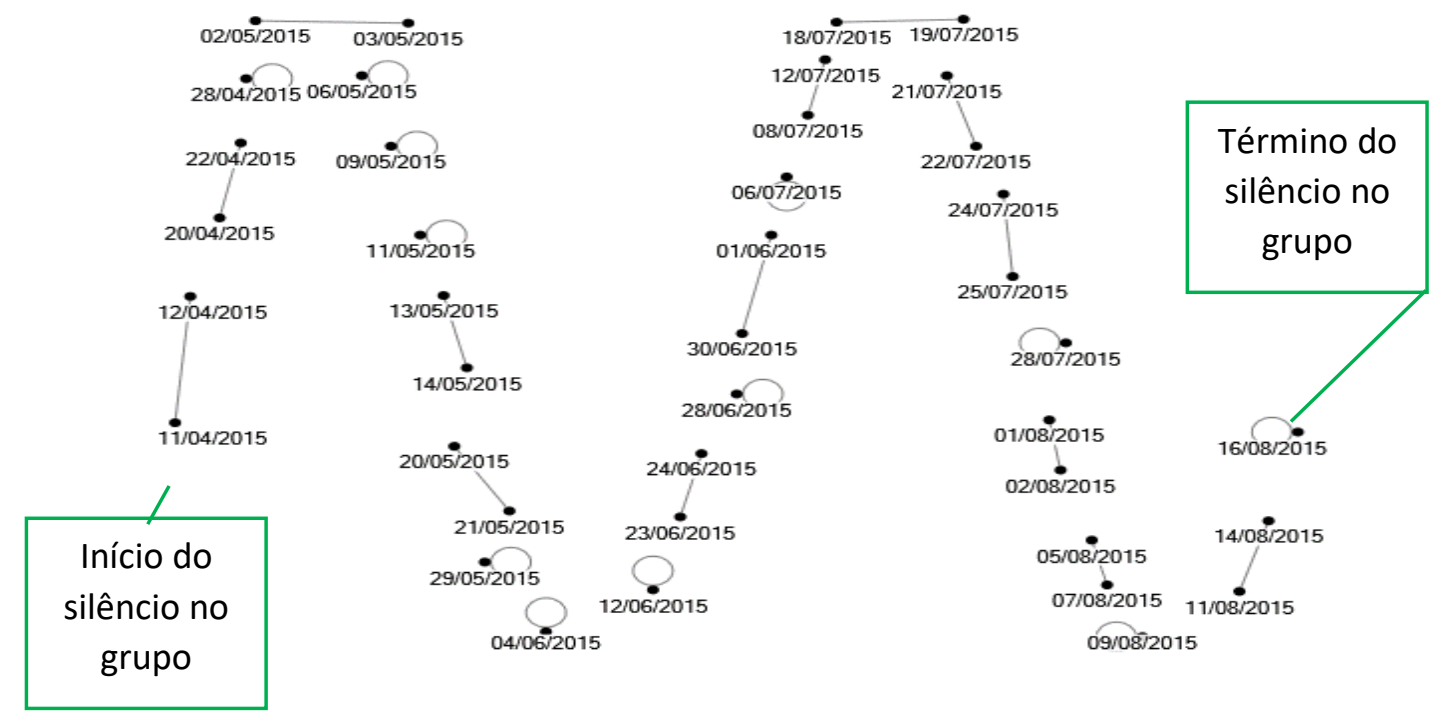

Fonte: Elaboração própria a partir do software nodexl.

\footnotetext{
${ }^{5}$ É um criador de gráficos para Excel que consegue visualizar os contatos da sua conta em redes sociais. O programa usa a ferramenta na própria interface do office, facilitando a visualização dos usuários acostumados com o editor da Microsoft. Tudo o que você tem de fazer para usar o programa é inserir dados. Disponível em: www.techtudo.com.br/tudo-sobre/nodexl.html. Acesso em: 18 outubro 2016. O conhecimento desse recurso se deu na disciplina cursada pelo primeiro autor desse artigo na disciplina ciberpesquisa-formação no PROPED/UERJ no segundo semestre de 2016.
} 


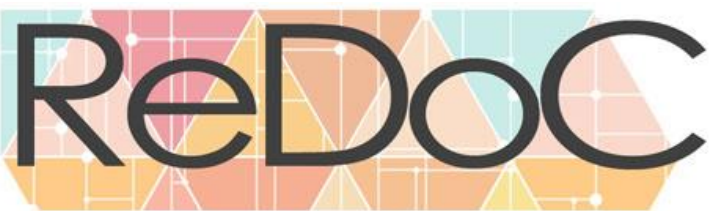

Revista Docência e Cibercultura

Os dados foram produzidos a partir de interações do início ao término do curso. Embora esteja retratando apenas a parte de hipertexto, fizemos o mapeamento de todas as datas que estão disponíveis na imagem acima. Ao analisar as datas, fizemos como foi dito anteriormente, analisando a data da postagem de cada publicação e as datas de seus comentários e qual foi o período que acontecia o silêncio na rede. No início da análise percebemos que entre os dias 11/04/2015 e 12/04/2015 a rede manteve-se em silêncio. O símbolo $\bigcirc$ que aparece por diversas vezes na imagem, refere-se a apenas um dia. Ou seja, um dia de silêncio na rede. Dessa forma, podemos notar que durante o período da disciplina, houve momentos que a rede se manteve em silêncio e em outros em constante ruído.

Esquema 2 - Ruídos na rede

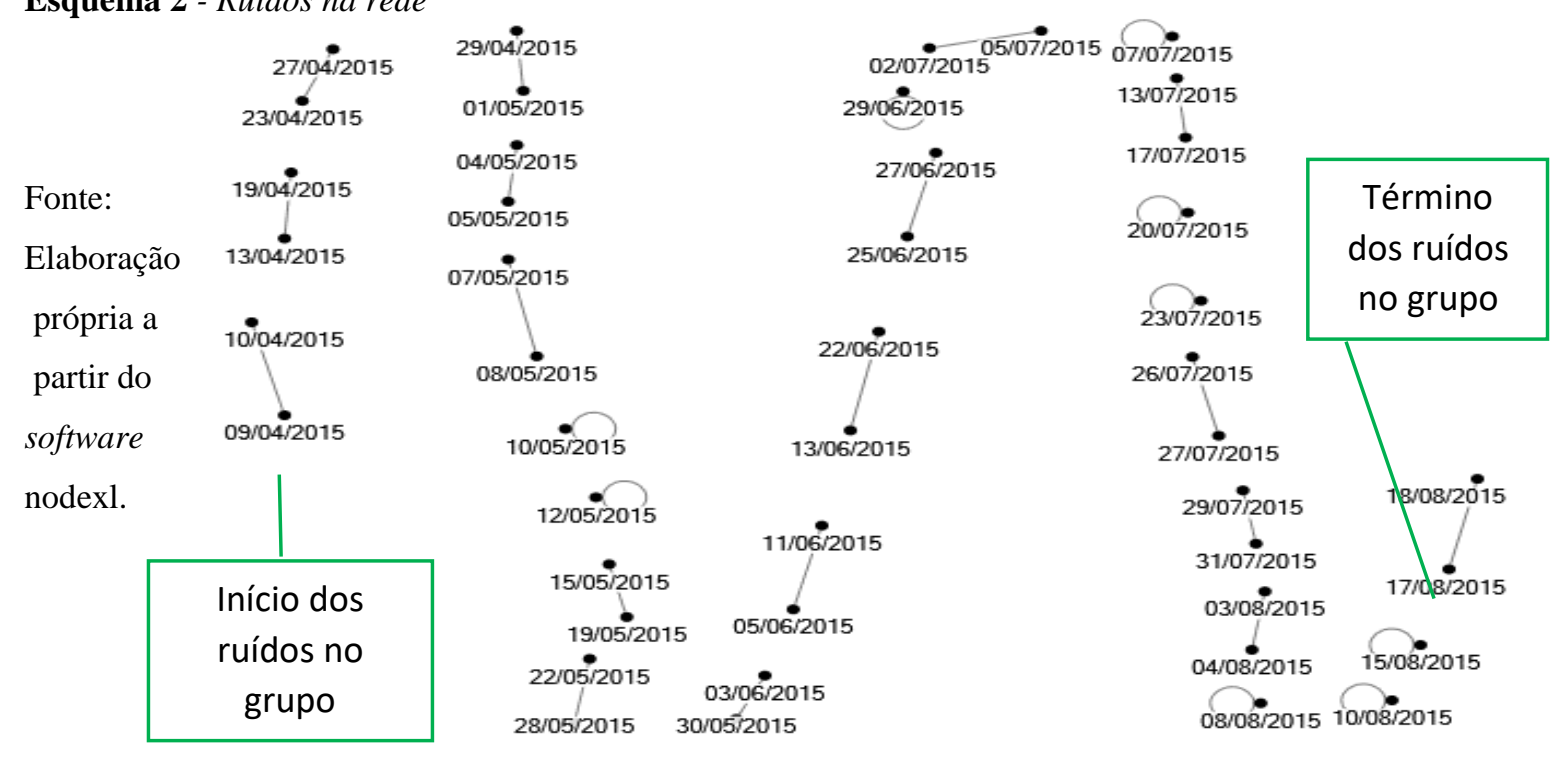

Comparando os dois esquemas, podemos ver que em alguns momentos o grupo foi silencioso, e em outros momentos bem barulhento. O símbolo encontrado no 


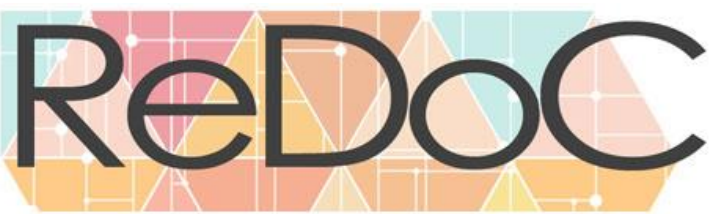

Revista Docência e Cibercultura

gráfico do silêncio repete-se na imagem do ruído demonstrando que em apenas um dia houve ruído, nos demais dias é possível ver que as interações foram maiores.

\section{CONSIDERAÇÕES FINAIS}

Neste artigo foi analisada uma experiência de implementação de uma disciplina optativa de mestrado em Educação mediante a criação de um grupo fechado no Facebook. A pesquisa esteve orientada pelo seguinte interrogante: Que ruídos e silêncios podem ser observados e que desafios à análise de interações neste espaço trazem para a pesquisa educacional? Articulando a esta questão, buscamos trazer contribuições para o uso institucional de grupos fechados no Facebook em disciplinas de pós-graduação, particularmente, ilustrando e criando esquemas para analisar as interações referentes ao conceito hipertexto debatido durante o processo de pesquisa.

Durante o processo de produção e observação de dados, encontramos dois pontos que achamos relevantes na pesquisa que nomeamos de ruídos e silêncios. Foram considerados ruídos, primeiramente partindo do conceito de fotografia, as imagens granuladas que ficavam ao subir e descer a barra de rolagem. Partindo dessa base, buscamos trazer, a partir deste conceito, a ideia de barulho que a própria palavra sugere, e tendo como contrapondo o silêncio que encontramos no grupo em alguns momentos.

Aqui estão exemplificados alguns ruídos que surgiram antes da efetivação da experiência, que surgiram a partir dos comentários dos colegas de turma e também de alguns professores com visões mais tradicionais. Os ruídos que apareceram durante a disciplina estavam relacionados às discussões que aconteciam no grupo e, após o término da disciplina, ficam relacionados aos eventos que participávamos e obtivemos algumas questões que nos ajudaram a pensar na importância da disciplina em um grupo fechado de uma rede social.

Os silêncios foram as marcas encontradas, através dos rastros silenciosos dos membros ao utilizar a rede. Por exemplo, consideramos silêncio na rede os interstícios existentes entre uma publicação e outra; além da visualização, que registrava quem via as postagens e a partir destas visualizações não se desdobravam em nada (ruídos). Embora 


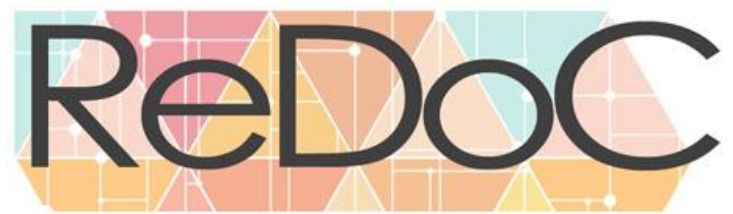

Revista Docência e Cibercultura

ruídos e silêncios muitas vezes estejam imbricados, optamos por deixá-los separados de modo a facilitar a construção de uma linha argumentativa que responda à questão de pesquisa. Pela fluidez, dinamicidade e horizontalidade comunicativa da rede social é desafiante capturar silêncios e ruídos e, sendo assim, cabe investigar os desafios dessa captura para a pesquisa e o aprendizado na contemporaneidade.

\section{REFERÊNCIAS}

BAIRRAL, M. A. Discurso, interação e aprendizagem matemática em ambientes virtuais a distância. Seropédica - RJ: edur, 2007.

BAIRRAL, M. A. A educação matemática em ambientes virtuais. Salvador - BA: Anais ... Encontro Nacional de Educação Matemática, 2010.

da SILVA, B. V. A. Curtir, interagir e aprender no Facebook. 2017. 124 p. Texto para Dissertação (Mestrado em Educação, Contextos Contemporâneos e Demandas Populares). Instituto de Educação / Instituto Multidisciplinar, Universidade Federal Rural do Rio de Janeiro, Seropédica, RJ. 2017.

da SILVA, B. V. A; BAIRRAL, M. A. DE ANTENAS PARABÓLICAS A REDES SOCIAIS: UM FOCO CONTÍNUO NAS TECNOLOGIAS E NA INCLUSÃO SOCIAL. In: VIII REDES SEMINÁRIO INTERNACIONAL, 2015, Rio de Janeiro. Anais... Rio de Janeiro: UERJ, 2015. p. 1-14.

MACEDO, N. M. R. Criancas e redes sociais: uma proposta de pesquisa on-line. In: PORTO, C., et al. Pesquisa e mobilidade na cibercultura: itinerâncias docentes. Salvador - BA: EDUFBA, 2015. p. 363-379.

MENDES, C. M. A pesquisa online: potencialidades da pesquisa qualitativa no ambiente virtual. hipertextus revista digital, Minas Gerais, v. 2, p. 1-9, janeiro 2009.

SANTOS, E. O.; CARVALHO, F. S. P.; PIMENTEL, M. MEDIAÇÃO DOCENTE ONLINE PARA COLABORAÇÃO: Notas de uma pesquisa-formação na cibercultura. Educação Temática Digital, Campinas - SP, v. 18, n. 2, p. 23-42, jan-abr 2016. ISSN 1676-2592. 